\title{
Measuring Organizational Performance of Small Medium Enterprise (SME) Printing Industry (Bandung, Jogjakarta, and Bali) using SCOR level 1 Opportunity Gap
}

\author{
Herry Irawan \\ School of Economics and Business, Telkom University \\ 40267 Bandung, Indonesia \\ herryir@telkomuniversity.ac.id
}

\author{
Ratih Hendayani \\ School of Economics and Business, Telkom University \\ 40267 Bandung, Indonesia \\ ratihhendayani@telkomuniversity.ac.id \\ Dodie Tricahyono \\ School of Economics and Business, Telkom University \\ 40267 Bandung, Indonesia \\ dodietricahyono@telkomuniversity.ac.id
}

\begin{abstract}
Every business, including SMEs should be ready in facing the globalization, such as Asean Economic Community (AEC) 2015. Most SMEs in developing countries such as in Indonesia still have low productivity, therefore they need to improve their performance. This study is focused on how to measure the organizational performance using Supply Chain Operation Reference (SCOR) Model Level 1 to define an opportunity gap in screen-printing business. Descriptive method was used to 67 respondents from three cities, Bandung, Yogyakarta, and Bali. The result shows that from three cities studied, Bali has the best performance since there is no performance gap found. This means that there is no lost opportunity, and they gain maximum profit. While the other two, gap performance is still found. To overcome the gap and improve the process, the Plan, Source, Make, Delivery, Return activities should be analyzed.
\end{abstract}

Keywords - Organizational Performance; Supply Chain Operation Reference; Perfect Order Fulfillment; screen-printing

\section{INTRODUCTION}

Small and Medium Enterprises have a central role in national economic. Unfortunately, it still has a domain of low productivity. In addition, most SMEs in developing countries such as in Indonesia have low penetration to develop their business. Therefore, they need to increase the performance and to develop their business so that they will be ready to face globalization, such as Asean Economic Community (AEC) 2015 (Hamdani, 2012 in Kurniawati and Yuliando, 2015) [1].

ASEAN officials have repeatedly emphasized the importance of SMEs, as the backbone of the regional economy. The process of regional economic integration is expected to encourage SMEs to upgrade their capabilities and narrow the development of gap among ASEAN economies. The problem relies on the lack of public awareness regarding the AEC's opportunities and challenges. Although there is a growing familiarity with the terms ASEAN and AEC, most SMEs still do not know what to expect and anticipate [2]. Factors such as education, government policy, business competition, and technology are supporting factors that enable SMEs to enhance their competitiveness [1].

Taticchi et.al. conclude in their research that for Small and Medium Enterprise (SME), the literature related with performance management appears immature and the models identified often fail while being implemented. They state that future research will focus on the creation of early conditions for Performance Measurement and Management (PMM) models implementation and on the development of specific PMM models tailored on SME characteristics and needs. [3]

Managing supply-chain operations is very important for any company's ability to compete effectively. Chopra and Meindl (2013) in Tajbakhsh (2015) define that supply chain is all parties and related processes that are involved in satisfying customer order. Using this definition, we can trace the different activities that are related to the customer order. [4] The supply chain has traditionally been managed as a series of simple, compartmentalized business functions. Sillanpää states that supply chain should be measured because management is interested in measuring how efficient supply chain is. [5]

The supply-chain operations reference model (SCOR) is the first cross-industry framework for evaluating and 
improving enterprise-wide supply-chain performance and management. SCOR is a tool for ensuring that the operations strategy has the desired outcome. Theeranuphattana and Tang in Sillanpää state that The SCOR model advocates hundreds of performance metrics used in conjunction with five performance attributes: reliability, responsiveness, flexibility, cost and asset metrics. [5]

Before using the model, a company must clearly define the basis of competition and make sure it is well understood by the entire management team. In addition, the operations strategy must be consistent with the company's overall business strategy [6].

Implementing SCM in developing countries, such as Malaysia and Indonesia, is still considered a major challenge, since there is a prerequisite. The prerequisite is the need to understand the requirements and behavior of SMEs in the context of SCM development. SMEs have their own unique characteristics that differentiate them from larger companies.

One conclusion is that if firms use maturity indicators in the Supply Chain Operations Reference areas to improve their processes, they will most likely achieve positive effects on supply chain performance and probably also on financial performance [7]. Many SMEs are lack knowledge that any empirical evidence regarding SCM development is a valuable path for SMEs to embark on. Small companies often do not have enough knowledge in house, and therefore they have to buy it from consultants (which can be expensive). If the knowledge about SCM and process management remain with the consultants outside SMEs, it may also be harder to adopt this as a method for improvements [8].

To overcome the competition that is stressed by the increasing supply chain, Supply Chain Council has suggested Supply Chain Operation Reference (SCOR) Model. The study shows that manufacturing industries are the biggest follower of the SCOR Model [9]. The supply-chain operations reference model (SCOR) is the first cross-industry framework for evaluating and improving enterprise-wide supply-chain performance and management [6]. SCOR can also be a tool for assessing Supply chain performance as stated in several researches, such [10], [11], [12], [13].

The goal of his research is discover the performance of SME Printing industry through SCOR analysis leve1 1. As stated in the previous research that with SCOR model the company can indicate their performance. The originality of this research is how the theory of SCOR analysis level 1 can be replicated in Small Medium Enterprise especially in the printing industry in Indonesia. In addition, this research may contribute to every small medium enterprise in the printing industry. In particular, the object of this research may address their performance and show the target for their maximum performance to improve their organizational performance.

\section{Methodology}

In this research, the method used is the descriptive causal method involving 67 people as respondents in the population from three cities. Moreover, for the benchmark industry, based on calculations performed by the Slovin's formula, it is obtained a minimum sample size of 90 printing businesses. In Bandung, the main object is the FA Collection with 38 businesses in the benchmark industry. In Yogyakarta, the main object is Mitra with 16 businesses in the benchmark industry. In Bali, the main object is Deddy Collection. Yet, since Bali only has a few in the business of screen-printing, the saturated samples are taken from 13 SMEs. The tools of analysis in this research are SCOR analysis at level 1. At level 1, calculation at the top level in the achievements scope, , is made in the form of the metric level 1. Level 1 Metrics are the basis of SCOR analysis, which crosses the measurement of high-level inter-process SCOR. Analysis on level 1 was originally done by defining the company's business objectives in accordance with that of the SCOR metric level 1. By knowing the company's business objectives, the analysis will focus on the areas that become the company's business objectives. After knowing the metrics that correspond to the company's business objectives, measurement of company performance in accordance with pre-defined metrics is performed. Further measurements is done by bench-marking against industry. At this stage the level metrics table 1 adds a new column which shows superior condition, advantage, and parity. Benchmark is performed to obtain a questionnaire distributed to the SME printing in Bandung, Yogyakarta and Bali. It is processed using the formula contained in the literature by finding the average of $20 \%$ for the highest value indicated by the superior [14], the lowest value, which is the middle value of statistical data indicated with parity, and the midpoint between parity and superior indicated the advantage [14]. After that, a comparison is made between the actual data of the company and another company, it is written in the column Requirement Gap. Once the Requirement Gap is known, which is actually the gap between the performance of the company with the comparison companies, an analysis is conducted on the opportunity that benefits the company. If the company has a performance higher or equal to the performance, then it is used as a comparison. At the end of level 1, the mapping of the general picture of the supply chain processes four main objects of each city. The data required for mapping is derived from observations and interviews openly with the business owners of the main objects that have been selected.

\section{RESUlt AND DisCUSSION}

In the printing industry in Bandung, Bali, and Jogja, the main product is printing screen. Based on the vision, mission and business focus, FA Collection makes shirts screen printing as desired by the consumer since they want to be a provider of screen printing with satisfactory products. In making the production of T-shirts, they are very cautious and detailed. This is related to the Reliability at SCOR, therefore the performance measurement will focus on Supply Chain Reliability with metric Perfect Order Fulfillment. 
TABLE I. The OPPORTUNITY GAP BASEd COMPANy PERFoRMANCE

\begin{tabular}{|l|l|c|c|c|c|c|c|}
\hline \multicolumn{1}{|c|}{ Performance Attribute } & \multicolumn{1}{|c|}{ Level 1 Metric } & Actual Data & Parity & Advantage & Superior & $\begin{array}{c}\text { Requirement Gap } \\
\text { (IDR) }\end{array}$ \\
\hline $\begin{array}{l}\text { Supply Chain Reliability } \\
\text { (BALI) }\end{array}$ & $\begin{array}{l}\text { Perfect Order } \\
\text { Fulfillment (POF) }\end{array}$ & $100 \%$ & $100 \%$ & $100 \%$ & $100 \%$ & 0 & 0 \\
\hline $\begin{array}{l}\text { Supply Chain Reliability } \\
\text { (BANDUNG) }\end{array}$ & $\begin{array}{l}\text { Perfect Order } \\
\text { Fulfillment (POF) }\end{array}$ & $93.8 \%$ & $100 \%$ & $100 \%$ & $100 \%$ & $6.2 \%$ & 3.100 .000 .000 \\
\hline $\begin{array}{l}\text { Supply Chain Reliability } \\
\text { (JOGJA) }\end{array}$ & $\begin{array}{l}\text { Perfect Order } \\
\text { Fulfillment (POF) }\end{array}$ & $92.2 \%$ & $92.5 \%$ & $95.63 \%$ & $98.75 \%$ & $6.55 \%$ & 2.350 .000 .000 \\
\hline
\end{tabular}

Based on the vision, mission and business focus, Dedy Collection makes shirts screen printing as desired by the consumer since they want to be a provider of screen printing with satisfactory products. In making the production of $\mathrm{T}$ shirts, they are very cautious and detailed. This is related to the Reliability at SCOR, therefore the performance measurement will focus on Supply Chain Reliability with metric Perfect Order Fulfillment. Based on interviews with the owner of Dedy Collection, it is known that Dedy Collection has the highest production on screen-printing tshirts. In Bali, many hamlets are major sources of income in stencil, youth - girls often order shirts for ceremonial purposes or banjo, which is often held in Bali. Mitra Konveksi focused on the production of new T-shirts with number 1 quality. The other products are jackets, shirts, hats, polo shirts, and sweaters. In addition, the materials used by Partners Konveksi also uses the selected material with the highest quality. This is related to the Reliability at SCOR, therefore the performance measurement will focus on Supply Chain Reliability with metric Perfect Order Fulfillment. Based on interviews with the owners, for products which are often in production, they focus on the production of cotton shirts. This shirt is ordered by his fellow students to the organization, for the events happening in Jogja.

After bench-marking with businesses in the printing industry, the gap between the performance of the three objects is then calculated, with a superior performance in the category. The magnitude of the gap is shown in the column performance requirement gap, which means that the gap is needed to set performance targets of the companies, which are equivalent or better than the performance in the superior category. To determine the value of superior category is by calculating the average value of the 18 highest values. To determine the value of the category of parity is by calculating the mean of all the data regarding the sample taken. To determine the value of the category is by calculating the value advantage midway between the superior and parity. After bench-marking with businesses in the printing industry, then the gap between the performance of the three objects is calculated, with a superior performance in the category. For the other subject in three other countries, the same calculation and the magnitude of the gap is used, as shown in the column performance requirement gap. This means that the gap is needed to set performance targets of the companies that, which are equivalent or better than the performance in the superior category as shown in Table 1.
After bench-marking with businesses in the printing industry screen printing shirts in Bali, known as Dedy Collection, there is no known performance gap so that the target company's performance has been on par with performance in the superior category. This means that there are no lost opportunities because the income earned is already at its the maximum profit, the Gross Profit: IDR. $15-35$ billion, whereas its Net Income: IDR. 5-10 billion. To perform calculations on the superior category, first calculations on the exact amount of about 20 percent of the samples taken are performed. The example calculation is from the Table 1, with Bandung objects as an example. The actual data from the result of an interview with the company, reveals the first calculation yielding that from 20 percent of the samples taken, only 8 data is actual. To determine the value of superior category is by calculating the average value of the 8 highest values. The superior category is 100 percent. Additionally, to determine the value of the category of parity is performed by calculating the mean of all the data regarding the sample taken.

The median value of the whole sample data is in the data on the order of 20 . By calculating the value, the middle two values reveals parity value of 100 percent. To determine the value of the category is performed by calculating the value advantage midway between the superior and parity. Therefore, the results from the calculation of the value in the superior category and parity that has been previously known are used. The opportunity in using the method to calculate the measure of lost opportunity revenue can be achieved if the company has the desired performance. This can be seen in the table at the outset to estimate the maximum opportunity to be gained by all companies with maximum total revenue is used for medium-sized companies. Under Law No. 20 of 2008 concerning SMEs, it is known that the maximum turnover for medium-sized enterprises is amounted to 50 billion rupiah. In addition, the completed result of the lost opportunity is shown in table 2 .

With regard to the actual POF and targets, the results can be achieved by multiplying the difference between the percentage of total revenue to a maximum (100) to the percentage of actual POF marked with (a). After multiplication of the total revenue by a margin of maximum percentage (100) to the percentage of POF, the target (100) is characterized by (b). It is then calculated the difference between (a) and (b) amounting to IDR 3.1 billion. With regard to the difference between (a) and (b) amounting to IDR 3.1 billion, the number is multiplied by gross profit FA Collection 
TABLE II. OPPORTUNITY POF CALCULATION WITH THE LOST OPPORTUNITY MEASURE

\begin{tabular}{|c|c|c|c|}
\hline Description & Bali & Bandung & Jogja \\
\hline Total Profit (Maximum) & 50.000 .000 .000 & 50.000 .000 .000 & 50.000 .000 .000 \\
\hline POF Actual & $100 \%$ & $93.8 \%$ & $92.2 \%$ \\
\hline POF Target (Superior) & $100 \%$ & $100 \%$ & $100 \%$ \\
\hline $\begin{array}{l}\text { Total Revenue X ((100- } \\
\text { POF Actual)/100) (a) }\end{array}$ & $\begin{array}{c}\text { IDR 50.000.000.000 X }((100-100) / 100) \\
= \\
\text { IDR 50.000.000.000 }\end{array}$ & $\begin{array}{c}\text { IDR } 50.000 .000 .000 \times((100- \\
93.8) / 100)= \\
\text { IDR 3.100.000.000 }\end{array}$ & $\begin{array}{c}\text { IDR } 50.000 .000 .000 \times((100-92.2) / 100)= \\
\text { IDR } 3.900 .000 .000\end{array}$ \\
\hline $\begin{array}{l}\text { Total Profit X ((100- } \\
\text { POF Target)/100) (b) }\end{array}$ & $\begin{array}{c}\text { IDR 50.000.000.000 X }((100-100) / 100) \\
=0\end{array}$ & $\begin{array}{c}\text { IDR } 50.000 .000 .000 \times((100- \\
100) / 100)=0\end{array}$ & $\begin{array}{c}\text { IDR 50.000.000.000 X }((100-98.75) / 100)= \\
\text { IDR. } 6.250 .000 .000\end{array}$ \\
\hline Min (a) dan (b) & $\begin{array}{c}\text { IDR 50.000.000.000-0 = IDR } \\
50.000 .000 .000\end{array}$ & $\begin{array}{c}\text { IDR 3.100.000.000-0 = IDR } \\
3.100 .000 .000\end{array}$ & $\begin{array}{c}\text { IDR 3.900.000.000 - IDR. } 6.250 .000 .000= \\
\text { IDR 2.350.000.000 }\end{array}$ \\
\hline Gross Profit (\%) & $100 \%$ & $100 \%$ & $100 \%$ \\
\hline $\begin{array}{c}\text { Gross Profit X Minus } \\
\text { (Opportunity) }\end{array}$ & $\begin{array}{c}100 \% \text { X IDR 50.000.000.000 }= \\
\text { IDR 50.000.000.000 }\end{array}$ & $\begin{array}{c}100 \% \text { X IDR } 3.100 .000 .000= \\
\text { IDR } 3.100 .000 .000\end{array}$ & $\begin{array}{c}100 \% \text { X IDR } 2.350 .000 .000= \\
\text { IDR } 2.350 .000 .000 \\
\end{array}$ \\
\hline $\begin{array}{l}\text { Loss Opportunity } \\
\text { (Maximum) }\end{array}$ & - & IDR 46.900.000.000 & IDR 47.650.000.000 \\
\hline
\end{tabular}

brochure. Gross profit in question is the percentage contribution to total revenue product brochures of FA Collection. With a percentage of 100 percent, it is then multiplied by a known amount of IDR 3.1 billion.

The opportunity owned by FA Collection is IDR 3.1 billion. The actual POF and targets in Mitra Konveksi, carried out by multiplying the difference between the percentage of total revenue to a maximum (100) to the percentage of actual POF is marked with (a). After multiplication of the total revenue by a margin of maximum percentage (100) to the percentage of POF, the target (100) is characterized by (b) then the difference between (a) and (b) amounting to IDR 2.35 billion is calculated. With regard to the difference between (a) and (b) amounting to IDR 2.35 billion, then that number is multiplied by gross profit Mitra Konveksi.

Therefore, although screen printing industry in Bali is the screen printing industry without performance gaps, that means has a better performance. However, based on the result from previous research, Tricahyono et al saying that every process that is based on SCOR Variables and on the basis of any details, the process of supply chain activities of the whole object in three towns have little differences in detail activity. Yet, they actually have a same process. It can be inferred that model business processes that can become a benchmark business process value chain for every SME printing industry in Indonesia and the completed supply chain business process by SCOR variables are screen printing industry in Jogja rather than those in Bali [12].

\section{CONCLUSION}

The screen-printing SME's can increase their performance if they can identify the performance gap and their lost opportunities. From this study, among four cities, Bali has the best performance with no performance gap found. It means that they can earn maximum profit. On the other hand, the other three cities, Jakarta, Bandung, and Yogyakarta still have performance gap, with different level. Even though Yogyakarta has best supply chain business process in detail, it is proven from the paper in previous research conducted by the same author with this research [15], it still has performance gap, compared with Bali. Therefore, the company should identify the opportunity for improvement derived from the Plan, Source, Make, Delivery, and Return activities.

\section{References}

[1] D. Kurniawati, and H. Yuliando, Competitive and Sustainable Agroindustry for Human Welfare Productivity Improvement of Small Scale Medium Enterprises (SMEs) on Food Products: Case at Yogyakarta Province, Indonesia. Agriculture and Agricultural Science Procedia 3, 2015, pp. $189-194$.

[2] R.W. Nandyatama, Indonesian SMEs and the ASEAN Economic Community. 2015, http://thediplomat.com/2015/06/indonesian-smesand-the-asean-economic-community/.

[3] P., Taticchi, F., Tonelli, and L. Cagnazzo, "Performance Measurement and Management: a Literature Review and a Research Agenda", Measuring Business Excellence, Vol. 14 no. 1, 2010, pp. 4-18

[4] A., Tajbakhsh, and E. Hassini,."Performance Measurement of Sustainable Supply Chains: a Review and Research Questions. International Journal of Productivity and Performance Management. Vol. 64 no. 6,2015 , pp. 744-783.

[5] I.. Sillanpää, "Empirical Study of Measuring Supply Chain Performance", Benchmarking: an International Journal, Vol. 22 no. 2, 2015, pp. 290-308

[6] G. Stewart. "Supply-chain Operations Reference Model (SCOR): the First Cross-industry Framework for Integrated Supply-chain Management”. Logistics Information Management, Vol. 10 Iss 2 1997, pp. $62-67$

[7] M.N. Rahman, "The Effective Implementation of Global Supply Chain Management in Small to Medium-sized Companies in Malaysia: an Empirical Study". International Journal of Management. Vol. 29 No. 3 Part 2 Sept 2012

[8] L. Söderberg, and L. Bengtsson. "Supply chain Management Maturity and Performance in SMEs". Operation Management Research. Vol 3, 2010, 90-97.

[9] S., Prakash, Soni, G., Sandeep, A.P.S. Rathore, "Supply Chain Operations Reference (SCOR) Model: An Overview and a Structured Literature Review of Its Application". International Conference on Smart Technologies for Mechanical Engineering. 25-26 October 2013.

[10] S.H., Eryuruk, S., Aydin, F., Kalaoglu, "Determining Performance Attributes Using SCOR Model to Compare Apparel Retailers". RMUTP Research Journal: Special Issue of 2014

[11] B.G. Jameeshooran, M.A. Shaharoun, H.N. Haron, "Asessing Supply Chain Performance Through Applying SCOR Model". International Supply Chain Management Journal. Vol. 4 No. 1, 2015. 
[12] B. Ruth, Supatn, Nucharee. "Developing a Supply Chain Performance Tool for Smash in Thailand". Supply Chain Management: An International Journal 16/1, 2011

[13] J. Thakkar, A. Kanda, \& S.G. Deshmukh, "Supply Chain Performance Measurement Framework for Small and Medium Scale Enterprises". Benchmarking: An International Journal, Vol.16, 2009.

[14] P. Bolstorff, and P. Rosenbaum, "Supply Chain Excellence", AMACOM, New York, 2007.
[15] D. Tricahyono, H. Irawan, R. Hendayani,"Mapping Supply Chain Management Business Process Model at Small Medium Enterprises Printing Industry in Indonesia Using Supply Chain Operation References Variable (Bandung, Yogyakarta and Bali)". Proceeding of The 6th Seminar and Conference on Business and Technoogy in ICT Industry, 2015. 